\title{
Anterior communicating artery division in the bifrontal basal interhemispheric approach
}

\author{
Torstein R. Meling ${ }^{1}$ (D)
}

Received: 11 June 2016 / Accepted: 15 June 2016 /Published online: 9 July 2016

(C) Springer-Verlag Wien 2016

Approaching deep-seated lesions in or around the thalamus/ hypothalamus or mesencephalon is challenging to even the most experienced neurosurgeon. Numerous surgical corridors, all carefully planned, patient-tailored and surgeon-tailored, have been used, including the basal anterior interhemispheric approach used in the current paper by Teramoto and Bertalanffy [10]. An inherent limitation common to all approaches, be it variants of the anterior interhemispheric approach (via unilateral subfrontal or bilateral basal corridors $[5,7,9])$ or the interhemispheric, trans-callosal, subchoroidal approach $[1,3,4,6,8]$, is the limited exposure due to critical neurovascular structures. Please check "(ref)".This refers to the article in Acta that my comments refers to - please insert here to replace the (ref).

In the anterior interhemispheric approach, the anterior communicating artery (ACOM) is one of these critical neurovascular structures that limit exposure. Previously, several eminent Japanese neurosurgeons [2, 7, 9] have demonstrated how a controlled ACOM division can obtaining a wider surgical exposure in the anterior interhemispheric fissure, but the method has failed to gain widespread use, probably due to the risk of serious complications related to ACOM perforator infarcts, as well as lack of documented effects on the surgical exposure of an ACOM sacrifice and lack of specific preoperative predictors of the need for ACOM division during a surgical procedure.

In their paper, Teramoto and Bertalanffy [10] sought to identify key factors that allow for predicting the necessity of

Torstein R. Meling

torevmel@online.no

1 Department of Neurosurgery, The National Hospital, University of Oslo, Sognsveien 0027, Norway controlled ACOM division in the bifrontal basal anterior interhemispheric approach (BBAIA). A total of 22 patients were operated using the BBAIA, of whom only eight required ACOM sacrifice. ACOM sacrifice was performed in two out of three thalamic lesions (67\%), in two out of five midbrain lesions (40\%), and in four out of 11 suprasellar or sellarsuprasellar lesions $(36 \%)$, but in none of the hypothalamic lesions. There were 14 central and eight lateral tumors. ACOM division was associated with tumor depth for centrally located tumors, and tumor laterality for lateral tumors. However, tumor size was not associated with a need for ACOM division in neither scenario. Please check "(ref)".This refers to the article in Acta that my comments refers to - please insert here to replace the (ref).

As the total number of cases is low, we should interpret the results with caution and refrain from making generalizations. For instance, the lack of effect of tumor size could be true, or merely a type II statistical error given the low number of cases. Furthermore, one inherent risk of the BBAIA is olfactory nerve damage and the state of postoperative olfaction is not reported. Thus, the article is more a proof of concept than a claim to "gold standard status".

Regrettably, the manuscript focused solely on the BBAIA and thus fails in describing or discussing alternative approaches to some of the lesions, something that would have been very useful when coming from an expert neurosurgeon like Prof. Bertalanffy.

The surgical results are, in general, excellent, and the authors document that no adverse effects of ACOM sacrifice were encountered in the eight patients. In this regard, the authors are to be congratulated. However, as the authors themselves point out, it was impossible to precisely identify perforating ACOM branches or an anomalous ACOM on general angiograms preoperatively and the assessment of a hypoplastic A1 segment or other variations was performed by direct 
inspection only intraoperatively. Consequently, it may well be that the authors' findings may predict the necessity for ACOM division preoperatively, but there is currently no way of determining the feasibility to do so preoperatively.

Lastly, I would welcome a cadaveric study, in the spirit of our late Dr. Rhoton, that measures and documents the increase in total area of surgical exposure of the suprasellar, hypothalamic and mesencephalic regions achieved by an ACOM division.

\section{References}

1. Cossu M, Lubinu F, Orunesu G, Pau A, Sehrbundt Viale E, Sini MG, Turtas S (1984) Subchoroidal approach to the third ventricle. Microsurgical anatomy. Surg Neurol 21:325-331

2. Fujitsu K, Sekino T, Sakata K, Kawasaki T (1994) Basal interfalcine approach through a frontal sinusotomy with vein and nerve preservation. Technical note. J Neurosurg 80:575-579. doi:10.3171/jns.1994.80.3.0575

3. Hosainey SA, Meling TR (2014) A 34-year-old woman with brainstem cavernous malformation: the anterior transcallosal transchoroidal approach and literature review. J Neurol Surg Rep 75:e236-240. doi:10.1055/s-0034-1387192
4. Lavyne MH, Patterson RH Jr (1983) Subchoroidal trans-velum interpositum approach to mid-third ventricular tumors. Neurosurgery 12:86-94

5. Mayfrank L, Reul J, Huffmann B, Bertalanffy H, Spetzger U, Gilsbach JM (1996) Microsurgical interhemispheric approach to dural arteriovenous fistulas of the floor of the anterior cranial fossa. Minim Invasive Neurosurg 39:74-77. doi:10.1055/s-20081052221

6. Rosenfeld JV, Harvey AS, Wrennall J, Zacharin M, Berkovic SF (2001) Transcallosal resection of hypothalamic hamartomas, with control of seizures, in children with gelastic epilepsy. Neurosurgery 48:108-118

7. Shibuya M, Takayasu M, Suzuki Y, Saito K, Sugita K (1996) Bifrontal basal interhemispheric approach to craniopharyngioma resection with or without division of the anterior communicating artery. J Neurosurg 84:951-956. doi:10.3171/jns.1996.84.6.0951

8. Siwanuwatn R, Deshmukh P, Feiz-Erfan I, Rekate HL, Zabramski JM, Spetzler RF, Rosenfeld JV (2005) Microsurgical anatomy of the transcallosal anterior interforniceal approach to the third ventricle. Neurosurgery 56:390-396, discussion 390-396

9. Suzuki J, Katakura R, Mori T (1984) Interhemispheric approach through the lamina terminalis to tumors of the anterior part of the third ventricle. Surg Neurol 22:157-163

10. Teramoto S, Bertalanffy H (2016) Predicting the necessity of anterior communicating artery division in the bifrontal basal interhemispheric approach. Acta Neurochir. doi:10.1007/s00701016-2884-3 